\title{
Editorial
}

\section{Una fuerza en crecimiento: El género femenino en urología}

\section{A growing force: the female gender in urology}

\author{
Herney Andrés Garcia-Perdomo ${ }^{10}$ \\ ${ }^{1}$ Departamento de Cirugía /Urología. Escuela de Medicina. \\ Universidad del Valle. Cali, Colombia \\ Urol Colomb 2020;29:179.
}

Aunque la urología continúa siendo una especialidad predominantemente masculina, durante los últimos años ha cambiado la composición. La representación femenina se ha incrementado alrededor de 11 veces desde 1978; un incremento mucho mayor que el visto en otras especialidades. ${ }^{1}$ En la actualidad las mujeres en urología representan alrededor del $10 \%$ de profesionales y $24 \%$ de los residentes ${ }^{1,2}$; sin embargo, de acuerdo con las proyecciones mundiales necesitamos más urólogos, por tanto, más mujeres en urología.

Aún tenemos múltiples factores que pueden limitar tanto el ingreso como la permanencia de las mujeres en el campo laboral, por ejemplo: los patrones de práctica, las promociones dentro del campo académico, el balance vida/trabajo y la equidad en salarios, entre otros. ${ }^{3}$ Sin embargo, en la actualidad estos se han ido sorteando de la mejor manera, comprendiendo que es una excelente especialidad para ambos géneros. ${ }^{4}$

Generalmente se ha descrito que el género puede afectar la carrera médica y el balance entre la vida/trabajo, argumentando que las mujeres trabajaban menos que los hombres. ${ }^{4}$ Sin embargo, la evidencia sobre la que describen esto es débil. Incluso hay estudios mostrando mujeres reportando menos horas de las que normalmente trabajan y hombres reportando mas horas. Además, otros estudios en los que las mujeres trabajan tiempo completo e igual número de horas que su contraparte masculina. ${ }^{5}$ De acuerdo con el reporte de 2014 de la Sociedad Americana de Urología, ${ }^{6}$ no hay diferencia entre el número de horas que trabajan los hombres $\mathrm{y}$ las mujeres (55 horas/semana). También refieren que las mujeres se dedican predominantemente ( 8 horas/semana vs 5 horas /semana) a labores no clínicas (administración, docencia e investigación), elementos fundamentales para el adecuado desarrollo de nuestra especialidad.

Por otro lado, las mujeres en urología pueden ser más jóvenes que su contraparte masculina. ${ }^{1}$ Esto conlleva que la fuerza laboral en algunos años esté liderada por las mujeres y se requiera estimular a más estudiantes y profesionales médicas para que ingresen a nuestra especialidad.

Para finalizar, quisiera exhortar a las estudiantes de medicina y las médicas a participar de nuestras actividades urológicas, y a nuestras residentes y urólogas a ser líderes en los diferentes grupos de trabajo y en cada uno de los escenarios en que se desempeñen. Requerimos un número mayor de mujeres líderes en nuestra especialidad quirúrgica, que se involucren tanto en la solución de problemas urológicos, así como en investigación y docencia en las universidades de Colombia y el mundo.

\section{Referencias}

1 Nam CS, Daignault-Newton S, Herrel LA, Kraft KH. The Future is Female: Urology Workforce Projection From 2020 to 2060. Urol-

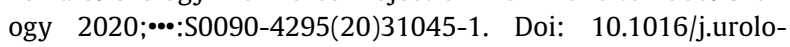
gy.2020.08.043 [Internet]

2 Halpern JA, Lee UJ, Wolff EM, et al. Women in Urology Residency, 1978-2013: A Critical Look at Gender Representation in Our Specialty. Urology 2016;92:20-25https://pubmed.ncbi.nlm.nih. gov/26952568/ cited20200ct25 [Internet]

3 Velez D, Ashok A, Greenberg R, et al. Rising Tides: Challenges and Opportunities for Women in the Urologic Workforce. Urology 2020:S0090-4295(20)30870-0

4 Saltzman A, Hebert K, Richman A, et al. Women Urologists: Changing Trends in the Workforce. Urology 2016;91:1-5. Doi: 10.1016/j.urology.2016.01.035 [Internet]

5 Lightner DJ, Terris MK, Tsao AK, Naughton CK, Lohse CM. Status of women in urology: based on a report to the Society of University Urologists. J Urol 2005;173(02):560-563https://pubmed.ncbi. nlm.nih.gov/15643253/ cited20200ct25 [Internet]

6 American Urological Association The State of the Urology Workforce and Practice in the United States 2014 [Internet] United States. 2014. Available from: http://www.auanet.org/common/pdf/research/census/State-Urology-Workforce-Practice-US.pdf

\footnotetext{
Address for correspondence Herney Andrés García-Perdomo, MD MSc, EdD, PhD, FACS, Departamento de Cirugía/Urología, Escuela de Medicina, Universidad del Valle, Cali, Colombia (e-mail: editorrevista@scu.org. co).
}

DOI https://doi.org/

10.1055/s-0040-1721328.

ISSN 0120-789X.

e ISSN 2027-0119.

\section{Copyright (c) 2020, Thieme Revinter Publicações Ltda.., Rua do Matoso 170, Rio de Janeiro, RJ, CEP 20270-135, Brazil. Todos los derechos reservados.}

